\title{
Feeding Behaviour of Mosquito Species in Mararraba-Akunza, Lafia Local Government Area, Nasarawa State, Nigeria
}

\author{
Ombugadu $\mathrm{A}^{1 *}$, Ekawu RA ${ }^{1}$, PamVA ${ }^{1}$, Odey $\mathrm{SA}^{1}$, Igboanugo $\mathrm{SI}^{2}$, Luka $\mathrm{J}^{2}$, Njila $\mathrm{HL}^{3}$, Ajah $\mathrm{LJ}^{1}$, Adejoh $\mathrm{VA}^{1}$,

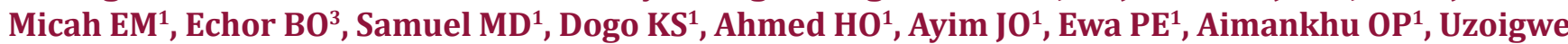 \\ $\mathrm{NR}^{1}$, Mafuyai $\mathrm{MJ}^{4}$, Yina GI ${ }^{5}$, Pam DD ${ }^{5}$, Lapang MP5 , Aliyu AA ${ }^{1}$, Ayuba $\mathrm{SO}^{1}$, Nkup $\mathrm{CD}^{6}$, Angbalaga GA7 and \\ Mwansat GS \\ ${ }^{1}$ Department of Zoology, Faculty of Science, Federal University of Lafia, Nasarawa State, Nigeria. \\ ${ }^{2}$ Department of Zoology, Faculty of Natural Sciences, Nasarawa State University, Keffi, Nigeria. \\ ${ }^{3}$ Department of Science Laboratory Technology, Faculty of Natural Sciences, University of Jos, Plateau State, Nigeria.
}

${ }^{4}$ Department of Pest Management Technology, Forestry Research Institute of Nigeria, Federal College of Forestry, Jos, Plateau State, Nigeria

${ }^{5}$ Department of Zoology, Faculty of Natural Sciences, University of Jos, Plateau State, Nigeria

${ }^{6}$ Department of Biology, College of Arts, Science and Technology, Kurgwi, Qua'an Pan LGA, Plateau State, Nigeria.

${ }^{7}$ Department of Microbiology, Faculty of Science, Federal University of Lafia, Nasarawa State, Nigeria.

*Corresponding author: Ombugadu A, Department of Zoology, Faculty of Science, Federal University of Lafia, Nasarawa State,

Nigeria, E-mail: akwash24@gmail.com

\section{ARTICLE INFO}

Received: 慧 January 17, 2020

Published: 蔧 January 27, 2020

Citation: Ombugadu A, Ekawu RA, Odey SA, Igboanugo SI, Luka J, Njila HL, et al. Feeding Behaviour of Mosquito Species in Mararraba-Akunza, Lafia Local Government Area, Nasarawa State, Nigeria Biomed J Sci \& Tech Res 25(1)-2020. BJSTR. MS.ID.004133.

Keywords: Mosquitoes Feeding Behaviour; CDC Light Trap; Temperature; Relative Humidity; Outdoor and Indoor Points; Man Biting Rate; Mararraba Akunza

Abbreivations: CDc: Centers for Disease Control; HLC: Human Landing Collection; CDC LT: CDC Light Trap

\section{ABSTRACT}

The knowledge on human-vectors contact is of great importance in order to tackle the point of transmission of mosquito-borne diseases through relevant control measures and interventions. To this end, a study on the feeding behaviour of mosquito species in Mararraba-Akunza, Lafia Local Government Area, Nasarawa State, Nigeria was carried out for 8 nights in May 2018 using modified CDC Light Traps set in indoor and outdoor points. The traps were suspended by the foot side of the bed having human bait laying under an untreated mosquito bed net. Mosquitoes were collected hourly between 6:00pm and 6:00am and transferred into well labelled paper cups. Hourly temperature and relative humidity were recorded using digital thermo-hygrometer. A total of 95 mosquitoes belonging to An. gambiae 49 (51.6\%) > Culex quinquefasciatus $40(42.1 \%)>$ Aedes aegypti $4(4.2 \%)>$ Mansonia uniformis $2(2.1 \%)$ were collected. The abundance of mosquitoes in relation to feeding points showed no significant difference $(\mathrm{P}>0.5)$. Outdoor point had higher abundance of 52 (54.7\%). The feeding behaviour in both points showed that mosquitoes feed most from 1:00 to 2:00am and decreased around 5:00 - 6:00am. The indoor and outdoor mosquitoes feeding time peaked at 9:00 - 10:00pm and 3:00 - 4:00am respectively. Temperature influenced indoor mosquitoes abundance while outdoor mosquitoes abundance was influenced by relative humidity. The indoors and outdoors man biting rate of mosquitoes per person per night was 5.0 and 5.9 respectively. Therefore, inhabitants of the area are encouraged to sleep under Long Lasting Insecticide Treated Nets in both points from dusk to dawn so as to prevent them from mosquitoes bites and consequently mosquito-borne diseases. 


\section{Introduction}

Mosquitoes are considered as serious problem everywhere because they proliferate in large number WHO [1] and are resistant to insecticides (Badolo et al. [2]; Oyewole et al. [3]; Awolola et al. [4]; Mwansat et al. [5]; Oduola et al. [6]; Lynd et al. [7]; SherrardSmith et al. [8]) leading to successful transmissions of malaria which is the leading cause of morbidity and mortality in Nigeria (WHO [9]). The mosquitogenic conditions are promoted by the anthropogenic activities and the creation and existence of several habitats throughout the year in the urban areas. The problem is more severe in rural areas especially because these areas are associated with well irrigated agroecosystems (Emidi et al. [10]). In these areas, poor sanitation facilities, usual agricultural practices and lack of sanitation facilities enhance the diversity and density of the population of mosquitoes and vector borne diseases. To control these remarkably adapted mosquitoes is a serious problem and therefore the mosquitoes peacefully co-exist with man. Many researchers have attempted to study the impacts of microhabitats and the differences in the behavioural patterns of vector and nonvector species of mosquitoes (WHO [1]).

The resting and feeding behaviour of mosquito is of great importance with respect to the efficacy of control measures. Indoor-based methods of control, such as the use of insecticideimpregnated bed nets and house-spraying with residual insecticides, are highly effective against mosquito species which mainly feeds indoors on humans and rests there once fed. Residual transmission is encouraged through mosquitoes bites outdoor which is a determinant of the maximum effectiveness on current prevention of mosquito-borne diseases (Sherrard-Smith et al. [8]). The degree to which other species feeds on non-human hosts and rests outdoors reduces the efficacy of these control methods, but also offers opportunities for other approaches (Reisen et al. [11]). An annual estimation of 10.6 million malaria cases across Africa is predicted to result due to higher outdoor transmission if universal coverage of LLIN and IRS is achieved (Sherrard-Smith et al. [8]).

Sampling vector populations in relation to surveys and compilation of checklist of species present in an area; identification of those species which bite man and determination of those that are important or potential vectors of disease is very essential Service [12]. The different aspects of mosquitoes are studied by many workers under different situations. Traps are effective surveillance tools for monitoring prevalence and the species composition of mosquitoes, along with reducing mosquito numbers nearby Moore, et al. [13].

Consequently, Centers for Disease Control (CDC) light traps hung beside occupied beds protected by bed nets remain a preferred alternative to an indoor human landing collection (HLC) for collecting host-seeking vectors over a wide range of mosquito densities Becker, et al. [14]. The CDC light traps are affordable, easy to use, and have relatively high sampling efficiency, although the relationship between CDC trap and indoor HLC collections needs to be verified locally for each study area because vector species composition and intraspecific variation in feeding and resting behaviour can have a significant impact on the quantitative association between the two methods Moore, et al. [13]. Thus, this study investigated the concurrent feeding behaviour of mosquito species in Mararraba-Akunza, Lafia Local Government Area, Nasarawa State, Nigeria.

\section{Materials And Methods}

\section{Study Area}

This study was carried out in Mararraba-Akunza area (Figure 1) of Lafia Local Government Area of Nasarawa State, Nigeria. Mararraba-Akunza area is a peri-urban settlement where various agricultural to anthropogenic activities takes place. Lafia is a town in central Nigeria (Latitude $8^{\circ} 24^{\prime} \mathrm{N}, 9^{\circ} 1^{\prime} \mathrm{E}$ and Longitude $8^{\circ} 13^{\prime} \mathrm{E}$, $9^{\circ} 8^{\prime} \mathrm{N}$ ). It has a total landmass of about $2797.53 \mathrm{~km}^{2}$ Lafia L.G.A shares boundary with Plateau State in the north east, Obi and Doma L.G.A in the South, Nasarawa Eggon in the West and Wamba LGA in the North. Nasarawa State is located in the North Central region of Nigeria with a land area of 27,137.8square kilometers. The main economic activities of the State is agriculture: cash crops such as yam, cassava and melon are grown Agidi, et al. [15]. Lafia L. G. A. has a tropical sub-humid climate, with two distinct seasons which are wet season and dry season. The wet season lasts for seven months which is between April and October, while the dry season is between November and March. Rainfall is moderately high in Lafia, ranging from $1200 \mathrm{~mm}$ to $1600 \mathrm{~mm}$. Average maximum and minimum daily temperatures are $35^{\circ} \mathrm{C}$ and $21^{\circ} \mathrm{C}$ in rainy season and $37^{\circ} \mathrm{C}$ and $16^{\circ} \mathrm{C}$ in dry season respectively Agidi, et al. [13].

\section{Sample Collection}

Mosquito samples were collected in accordance to the standard by AIRS Nigeria [17]. The night catch of mosquitoes was carried out between the hours of 6:00pm to 6:00am for eight nights in May 2018 using the modified CDC light trap (CDC LT) concurrently in both indoor and outdoor points. One trap was set up at each point. The trap was suspended 1.5 meters above the floor. The trap was hung by the foot side of the bed where human bait was lying down under an untreated mosquito bed net. The temperature and relative humidity was taken hourly for each point using digital thermometer and hygrometer. Mosquitoes trapped in the collection bag were transferred hourly into well labelled paper cups indicating the hour and point of catch. A mesh was placed on top of the cups and held by a rubber band/ring so as to prevent mosquitoes from escaping. The samples were later transported to the insectary for sorting and morphological identification with the aid of a dissecting microscope. 


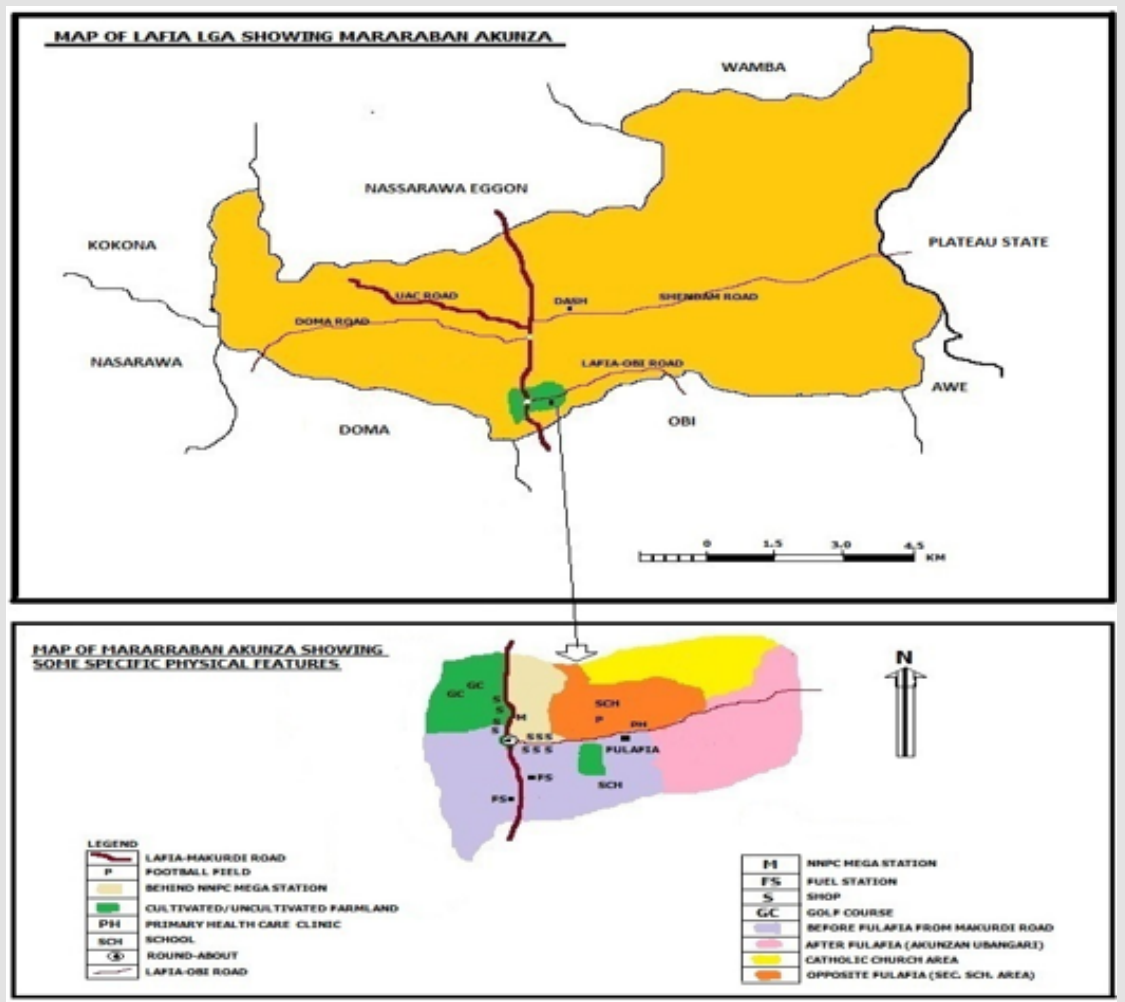

Figure 1: Map of Lafia LGA, Nasarawa State showing Mararraba-Akunza area and map of Mararraba-Akunza area showing some specific physical features (Source: Jibril, [16]).

\section{Morphological Identification and Preservation of Samples}

Mosquitoes were identified using morphological keys by Gillies, and De Meillon [18], Gillies and Coetzee [19] and Kent [20]. Samples were sorted according to species, sex, abdominal conditions, time, catch point, and then counted. All mosquitoes collected were then preserved in $1.5 \mathrm{ml}$ eppendorf tubes containing silica gel desiccant beneath a layer of cottonwool.

\section{Statistical Analysis}

Man Biting Rate (MBR): this is expressed as the number of bites a person receives from a specific vector species per night. This parameter can indirectly be estimated from mosquito day or night catches (e.g. PSC, HLC, CDC LT) using the formula by Williams and Pinto [21] below:

\section{$M B R=\frac{\text { Number of mosquitoes collected }}{\text { Number of people that slept in the prevoius night }}$}

MBR $=$ (Number of mosquitoes collected)/(Number of people that slept in the rooms the previous night). Data obtained was analyzed using R Console software (Version 3.2.2). Pearson's Chisquare test was used to compare abundance between mosquito groups, gender and as well as culicine species. Welch two sample t-test was used to compare abundance of mosquitoes in relation to feeding points. Two-way ANOVA was used to compare abundance of mosquitoes in relation to time and feeding points. Pearson's product-moment correlation was used to determine the association between mosquito abundance and physico-chemical parameters in relation to feeding points. The P-value $<0.05$ was considered statistically significant.

\section{Results and Discussion}

\section{Composition of Mosquitoes in Mararraba-Akunza Area, Lafia LGA, Nasarawa State, Nigeria}

Results obtained showed that the study area is populated by anopheline (Anopheles gambiae as shown on Plate 1) and culicine mosquitoes (Culex quinquefasciatus and Aedes aegypti on Plate 2 and plate 3) as shown in Table 1. This possibly suggests the likelihood that the inhabitants of Mararaba-Akunza community may be infected with various mosquitoes-borne diseases if beaten by mosquitoes carrying infective stage of any of the parasite gotten from an infected person while feeding on blood meal host. The four diverse mosquito species recorded in this study showed that the human-baited CDC light trap is an efficient mosquito sampling tool. This is in agreement with the finding by Ezeigwe, et al. [22] who trapped five Anopheles species via the CDC light trap ina study on Anopheles species diversity, behaviour, and sporozoite rates in six states of Nigeria. Also, this in an agreement with the finding of Sriwichai, et al. [23] who reported the effectiveness of CDC light trap on mosquito surveillance in a malaria endemic area on the Thai-Myanmar border in Thailand. 
Table 1: Mosquitoes trapped in Relation to Feeding Points in Mararraban-Akunza Area, Lafia LGA, Nasarawa State, Nigeria Using CDC Light Trap, May 2018.

\begin{tabular}{|c|c|c|c|c|c|c|c|}
\hline Sex & \multicolumn{2}{|c|}{ An. gambiae } & \multicolumn{2}{c|}{ Culicine } & \multicolumn{2}{c|}{ Sub-Total (\%) } & Total (\%) \\
\hline & Indoor & Outdoor & Indoor & Outdoor & Indoor & Outdoor & $5(62.5)$ \\
\hline Male & 1 & 0 & 2 & 5 & $3(37.5)$ & $4(8.4)$ \\
\hline Female & 21 & 27 & 19 & 20 & $40(46.0)$ & $47(54.0)$ & $87(91.6)$ \\
\hline Sub-Total (\%) & $22(44.9)$ & $27(55.1)$ & $21(45.7)$ & $25(54.3)$ & $43(45.3)$ & $52(54.7)$ & \\
\hline Total (\%) & \multicolumn{2}{|c|}{$49(51.6)$} & \multicolumn{4}{|c|}{$95(48.4)$} & \\
\hline
\end{tabular}

Note: Abundance between anopheline and culicine mosquitoes: $\chi^{2}=0.1024, \mathrm{df}=1, \mathrm{P}=0.749^{\text {ns }}$

Abundance between female and male mosquitoes: $\chi^{2}=69.222$, df $=1, \mathrm{P}<0.0001^{*}$

ns: Not significant

*: Significant

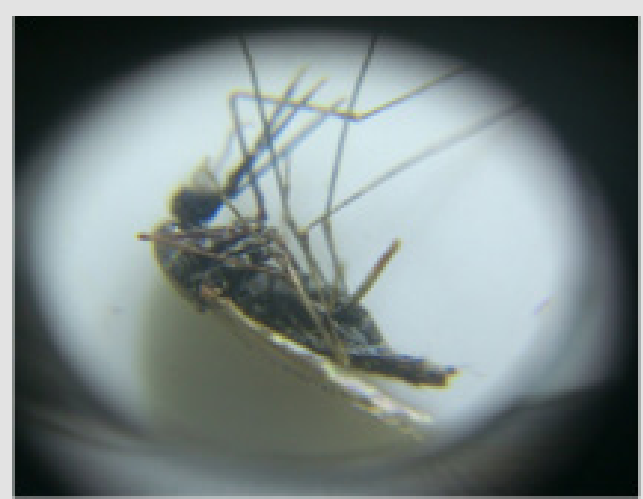

Plate 1: Anopheles gambiae.

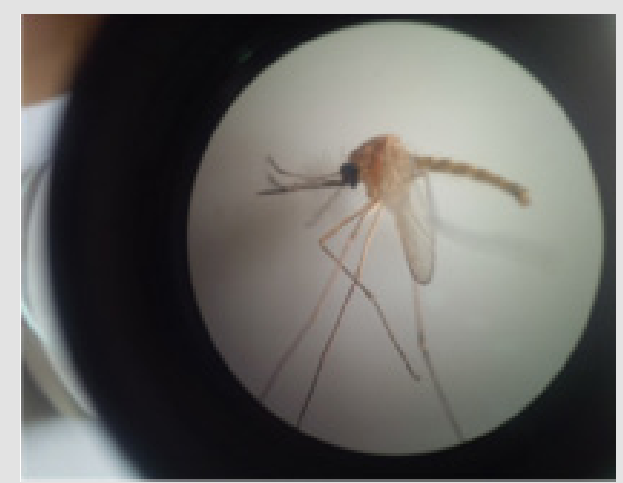

Plate 2: Culex quinquefasciatus.

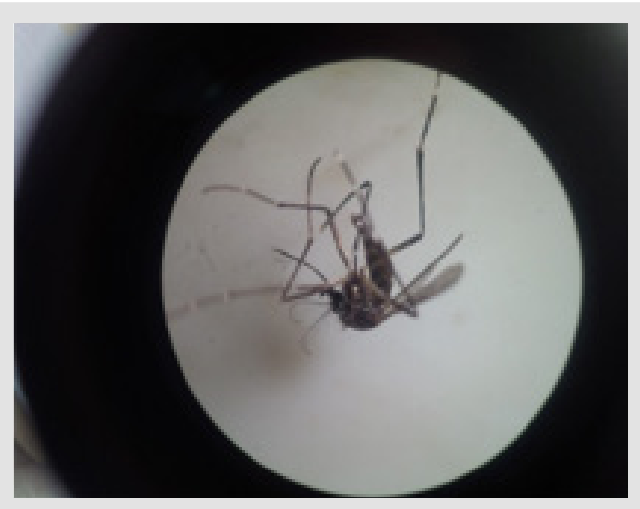

Plate 3: Aedes aegypti.

\section{Mosquitoes Abundance}

Of the 95 individuals collected, Anopheles gambiae was more dominant 49 (51.6\%) than the culicine mosquitoes $46(48.4 \%)$ as shown in Table 1. There was however no significant difference between the abundance of anopheline and culicine mosquitoes $\left(x^{2}=\right.$ $0.1024, \mathrm{df}=1, \mathrm{P}=0.749$ ). This is accordance with the finding by Sriwichai, et al. [23] who reported no significant variation in abundance between the two mosquitoes groups. Anopheles gambiae was the most abundant mosquito collected from both indoor and outdoor points (Table 1). This possibly suggests that the area is a good breeding ground (based on the presence of farmlands such as rice paddy fields and animal hoofs) for malaria vector which invariably will increase the risk of malaria transmission in the area. This agrees with the findings of Ezeigwe, et al. [22] who reported high number of Anopheles species over culicine group using same trap. This stands in contrast to study by Sriwichai, et al. [23] who used the $\mathrm{CO}_{2}$ baited $\mathrm{CDC}$ light traps and found Culex quinquesfasciatus as the predominant mosquito species in both indoor and outdoor points. Also, the finding of Norma, et al. [24] showed that Culex quinquefasciatus had the highest number of individuals in feeding points with more mosquitoes trapped at a municipality of Niterói a coastal residential district along a $700 \mathrm{~m}$ beach in Brazil. Consequently, Sherrard-Smith, et al. [8] reported some evidence for more outdoor biting for mosquito species that were not An. gambiae s.l. or An. funestus.

Aedes aegypti was one of the least predominant mosquito in the area (Table 1). This may probably be due to the fact that they are diurnal mosquitoes and the CDC light trap was set up to collect nocturnal mosquitoes from dusk to dawn. This is in line with previous study by Sriwichai, et al. [23] who set up same time and collected very few Aedes aegypti in comparison to other mosquito species. Most of the collected mosquitoes were female 87 (91.6\%) than males 8 (8.4\%) (Table 1) with significant difference between the abundance of female to male mosquitoes $\left(x^{2}=69.222, \mathrm{df}=1\right.$, $\mathrm{P}<0.0001$ ). This clearly shows that there will be a very high human-vector contact as females go in search of blood meal host. This is in accordance with the report by Sriwichai, et al. [23] who 
showed that more females (94\%) were collected over male mosquitoes in Thai-Myanmar border of Thailand.

Table 2 showed that $C x$. quinquefasciatus was the most dominant $40(87 \%)$ amongst the culicine mosquitoes followed by Ae. aegypti 4 (8.7\%) and the least 2 (4.3\%) was Mn. uniformis. Therefore, there was a very high significant difference $\left(x^{2}=129.9, \mathrm{df}=2, \mathrm{P}<\right.$

Table 2: Checklist of Culicine Mosquitoes trapped in Relation to Feeding Points in Mararraban-Akunza Area, Lafia LGA, Nasarawa State, Nigeria Using CDC Light Trap, May 2018.

\begin{tabular}{|c|c|c|c|c|c|c|c|}
\hline \multirow[t]{2}{*}{ Sex } & \multicolumn{2}{|c|}{ Ae. Aegypti } & \multicolumn{2}{|c|}{ Cx. quinquefasciatus } & \multicolumn{2}{|c|}{ Mn. uniformis } & \multirow[t]{2}{*}{ Total (\%) } \\
\hline & Indoor & Outdoor & Indoor & Outdoor & Indoor & Outdoor & \\
\hline Male & 0 & 0 & 2 & 6 & 0 & 0 & 8 (17.4) \\
\hline Female & 2 & 2 & 16 & 16 & 1 & 1 & $38(82.6)$ \\
\hline Sub-Total & 2 & 2 & 18 & 22 & 1 & 1 & \\
\hline Total (\%) & \multicolumn{2}{|c|}{$4(8.7)$} & \multicolumn{2}{|c|}{$40(87.0)$} & \multicolumn{2}{|c|}{$2(4.3)$} & 46 \\
\hline
\end{tabular}

Note: Abundance between culicine species: $\chi^{2}=129.9, \mathrm{df}=2, \mathrm{P}<0.0001^{*}$

*: Significant

\section{Mosquitoes Abundance In Relation to Feeding Points}

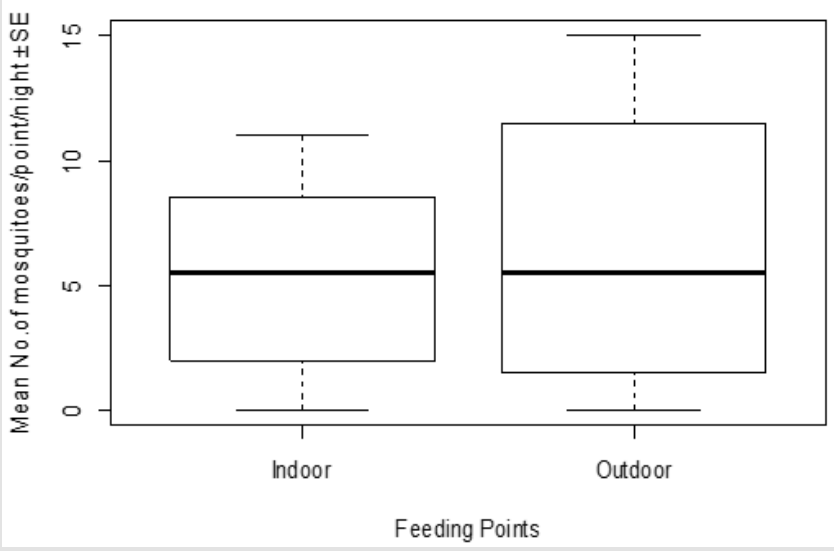

Figure 2: Mean abundance of mosquitoes across feeding points per night.

The outdoor point had higher abundance of mosquitoes caught $52(54.7 \%)$ as compared to the indoor point $43(45.3 \%)$. Nevertheless, the abundance of mosquitoes in relation to feeding points showed no significant difference $(\mathrm{t}=-0.43308 \mathrm{df}=12.516$, $P=0.6723$ ) as shown in Figure 2. The lack of variation in the abundance of mosquitoes in relation to feeding points possibly suggests have no preferred feeding point and the amount of $\mathrm{CO} 2$ being exhaled by the human baits laying down under the untreated bed nets may be equal alongside microclimatic conditions. On the contrary, Sherrard-Smith, et al. [8] reported that Burkina Faso, Eritrea, Ethiopia, Gabon, and Tanzania had relatively low proportions of mosquitoes feeding when people were indoors and in bed. Also, studies by Saavedra et al. [25] in riverine communities in the Peruvian Amazon showed that there were more anophelinae collected consistently in the peridomestic area outdoors compared with inside houses. Likewise, Sriwichai, et al. [23] collected more mosquitoes outdoor than indoor. Furthermore, the proportion
0.0001 ) in abundance between culicine species. The dominance of $C x$. quinquefasciatus over other members in the culicine group may be due to the nature of the settlement of the study area which is peri-urban with a lot of stagnant water bodies in the neighborhood which serves as a good breeding ground for such species. Similarly, Sriwichai, et al. [23] showed that Culex species was the most predominant within the culicine group. 
Pattern of Mosquitoes Peak Feeding Time in Relation to

\section{Points}

Concurrent mosquitoes feeding time peaked in indoor and outdoor points at 9-10pm and 3-4am respectively with 9 individuals each as shown in Table 3 . This is probably due to variations in microclimatic conditions (temperature and relative humidity) at each point per collection time. Accordingly, Ngowo, et al. [25] recorded that variations in household microclimate affect outdoor-biting behaviour of malaria vectors in four villages in south-eastern Tanzania. Anopheles gambiae feeding peaked at 9-10pm and10-11pm/3-5am at indoor and outdoor points having
6 and 4 individuals respectively (Figure 3). This result agrees with the finding of AIRS Nigeria [14] which reported that An. gambiae had high feeding peak between $2 \mathrm{am}$ and $4 \mathrm{am}$. Cx. quinquefasciatus feeding peaked at 1-2am and 3-4am in indoor and outdoor points respectively with 5 individuals each (Figure 4). Aedes aegypti feeding peaked at $6-7 \mathrm{pm}$ and $8-9 \mathrm{pm} / 11 \mathrm{pm}-12 \mathrm{am}$ in indoor and outdoor with an individual each (Figure 5). Mansonia uniformis feeding peaked at 9-10pm and 2-3am in indoor and outdoor points with 1 individual (Figure 6). Similarly, AIRS Nigeria [17] reported that the feeding peak time for culicine species was between 1-2am at the indoor and outdoor respectively.

Table 3: Mosquito Abundance in Relation to Feeding Time and Points.

\begin{tabular}{|c|c|c|c|}
\hline Time & No. of Mosquitoes in Points & Total \\
\hline & Indoor & Outdoor & 3 \\
\hline $6-7 p m$ & 2 & 1 & 6 \\
\hline $7-8$ & 3 & 3 & 6 \\
\hline $8-9$ & 2 & 4 & 14 \\
\hline $9-10$ & 9 & 5 & 9 \\
\hline $10-11$ & 3 & 6 & 11 \\
\hline $11-12$ & 3 & 5 & 15 \\
\hline $12-1$ am & 6 & 5 & 6 \\
\hline $1-2$ & 8 & 3 & 12 \\
\hline $2-3$ & 3 & 9 & 5 \\
\hline $3-4$ & 3 & 4 & 0 \\
\hline $4-5$ & 1 & 0 & 94 \\
\hline $5-6 a m$ & 0 & 52 & \\
\hline Total & 42 & & \\
\hline
\end{tabular}

Note: Abundance between time and feeding points: $\mathrm{F}_{179}=1.456$, Adjusted $\mathrm{R}^{2}=0.02786, \mathrm{P}=0.1447^{\mathrm{ns}}$

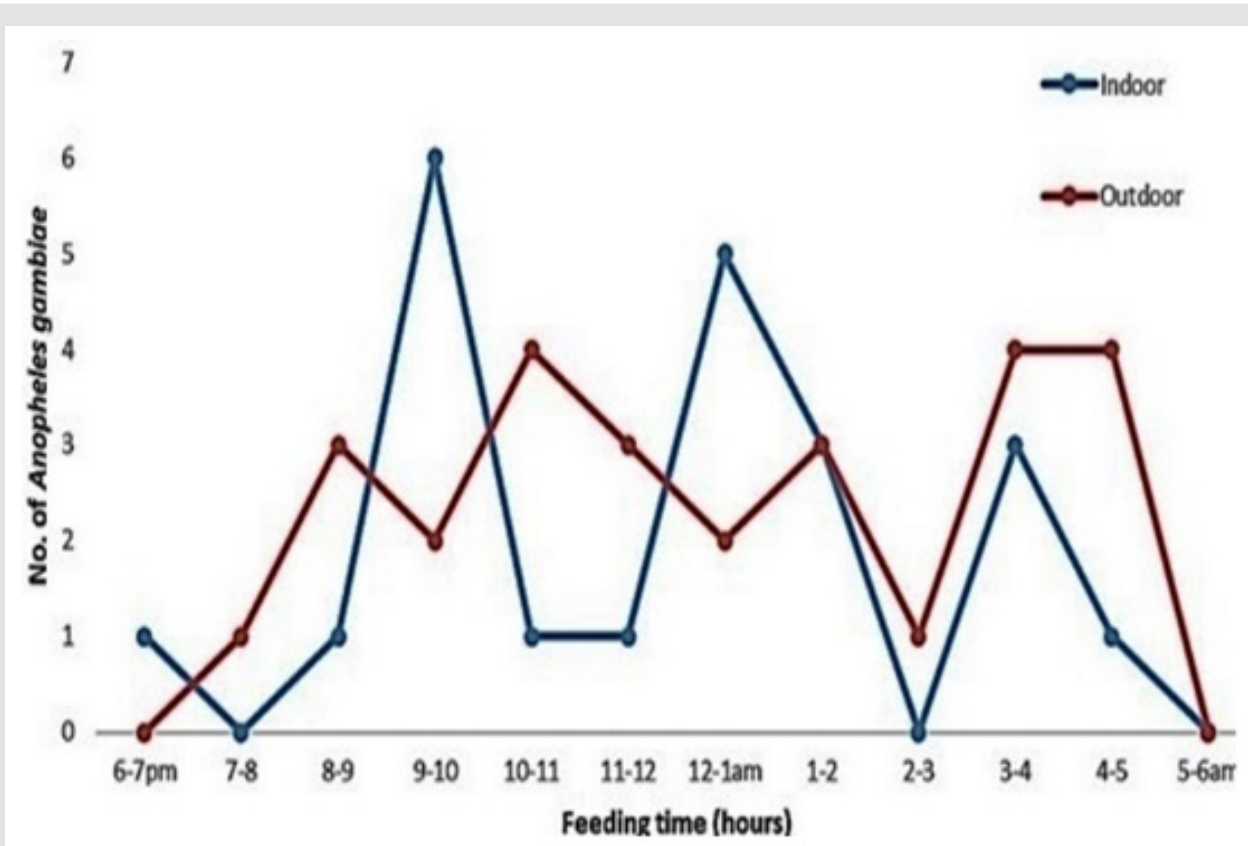

Figure 3: Feeding behavior of Anopheles gambiae in relation to hourly collection time. 


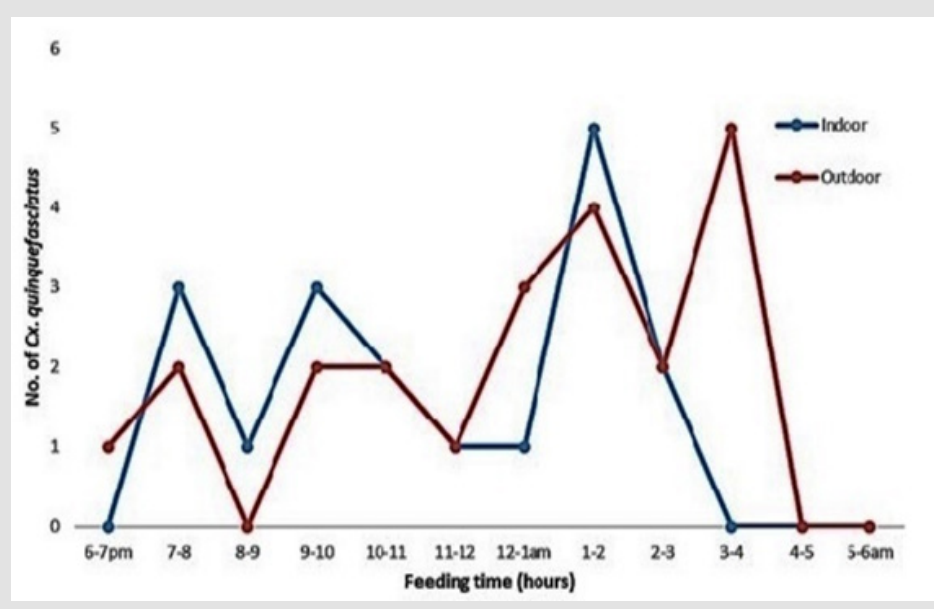

Figure 4: Feeding behavior of $C x$. quinquefasciatus in relation to hourly collection time.

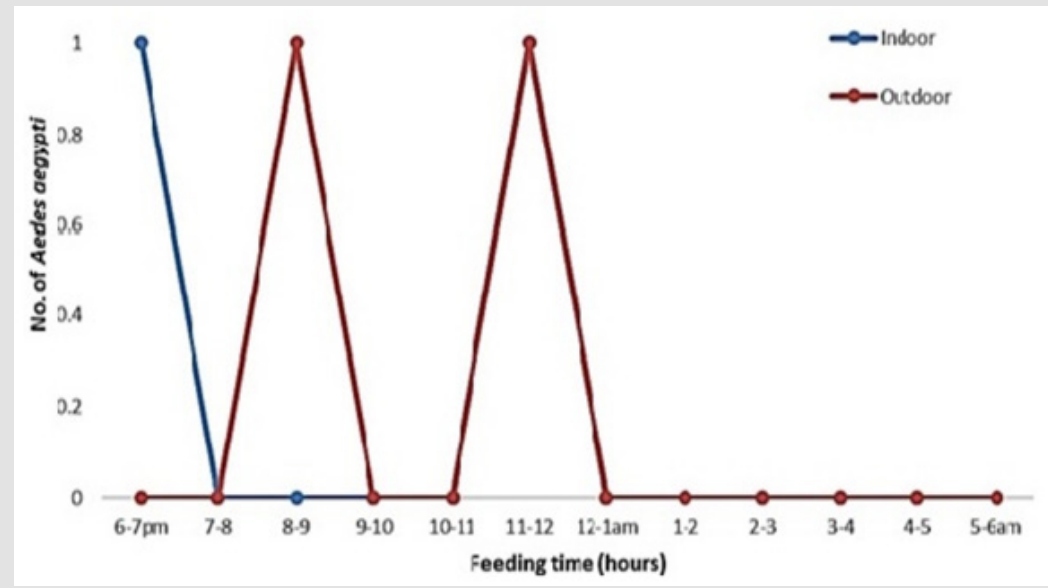

Figure 5: Feeding behavior of Aedes aegypti in relation to hourly collection time.

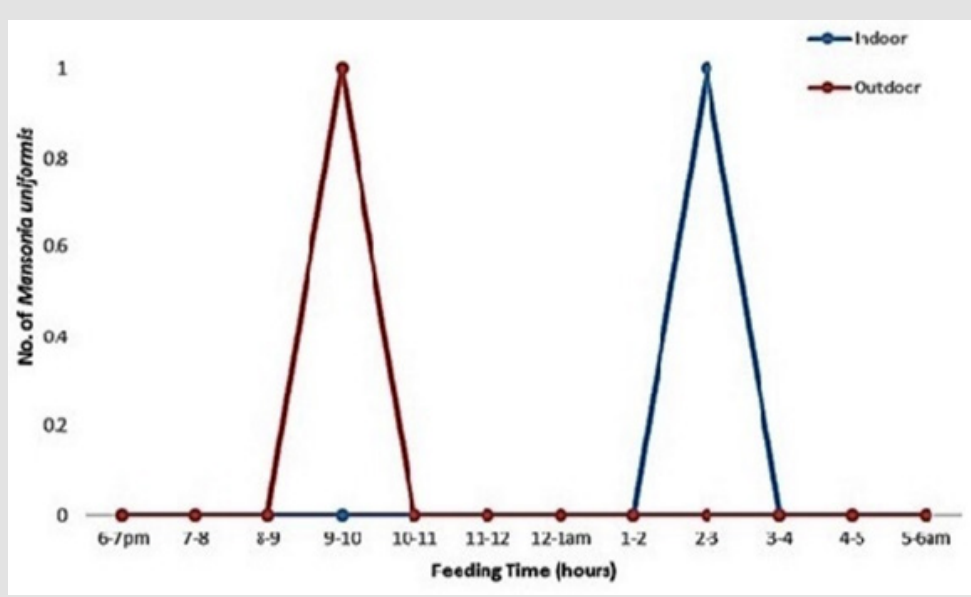

Figure 6: Feeding behavior of Mansonia uniformis in relation to hourly collection time.

Association between Mosquito Abundance and Physico-

\section{chemical Parameters within Feeding Points}

Indoor: Mosquitoes abundance indoor showed a weak positive association with temperature $(\mathrm{t}=0.57654, \mathrm{df}=94, \mathrm{P}=0.5656, \mathrm{r}$ $=0.05936096$, Figure $7 \mathrm{a}$ ) but negatively associated with relative humidity $(\mathrm{t}=-0.65621, \mathrm{df}=94, \mathrm{P}=0.5133, \mathrm{r}=-0.06752828$,
Figure $7 \mathrm{~b}$ ). The weak positive influence of indoor temperature on mosquitoes abundance may probably be due to the fact that temperature did not reach the maximum threshold (Figure 7a) as described by Mordecai, et al. [30]. This is inconsistent with the observation by Ngowo, et al. [29] in south-eastern Tanzania that a $1^{\circ} \mathrm{C}$ rise in the relative difference between indoor and outdoor temperature will prominently tend to drive out mosquitoes 
outdoor thereby increasing exophily An. funestus abundance by $\sim 66 \%$ and a marginal nightly increase in An. arabiensis abundance by $\sim 11 \%$. Also, previous studies have shown that An. arabiensis and An. gambiae s.s. are capable of detecting and responding to an increase in temperature of a few degrees through the use of thermohygroreceptor cells which makes them assess microclimatic conditions and modify their behaviour (Kirby and Lindsay [31]; Kessler and Guerin [32]; Paaijmans et al. [33]).

Outdoor: The abundance of mosquitoes outdoor negatively

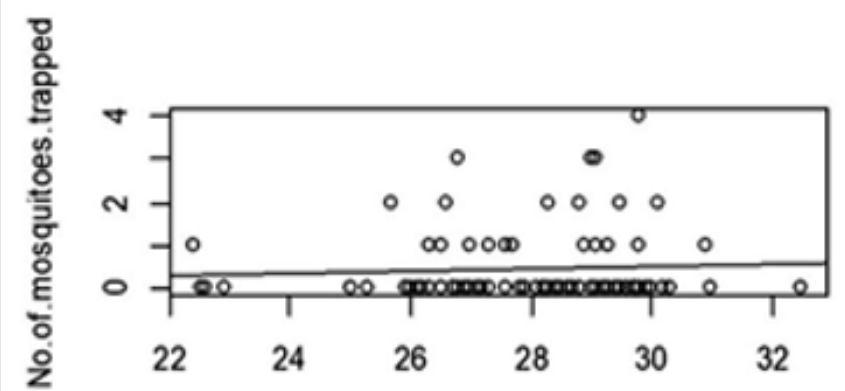

Figure $7 \mathrm{a}$. Indoor Temperature $\left({ }^{\circ} \mathrm{C}\right)$

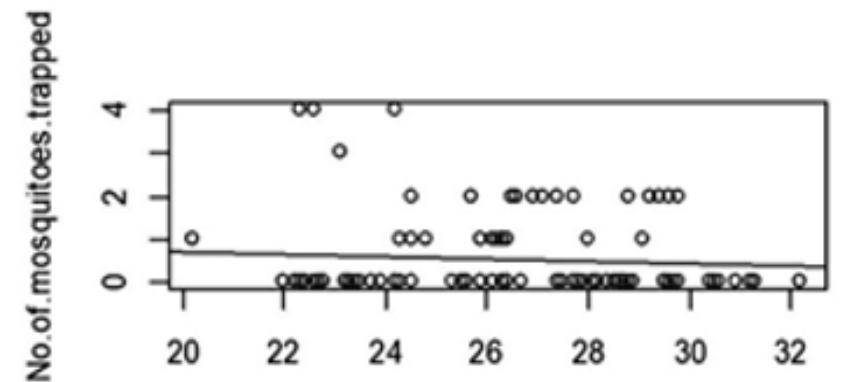

Figure $7 \mathrm{c}$. Outdoor Temperature $\left({ }^{\circ} \mathrm{C}\right)$ associated withwith outdoor temperature $(\mathrm{t}=-0.61791, \mathrm{df}=94$, $\mathrm{P}=0.5381, \mathrm{r}=-0.06360321$, Figure $7 \mathrm{c}$ ) while relative humidity positively associated with mosquitoes abundance at outdoor point $(\mathrm{t}=0.93477, \mathrm{df}=94, \mathrm{p}$-value $=0.3523, \mathrm{r}=0.09596935$, Figure $7 \mathrm{~d})$. The influence of relative humidity on mosquitoes abundance at outdoor point may be due to consistent rise in outdoor relative humidity. This is consistent with the findings of Kessler, et al. $[28,25]$ who recorded that mosquitoes move towards a more humid location. Also, a rise in indoor relative humidity will result to a decrease in exophily mosquitoes abundance Ngowo, et al. [25].
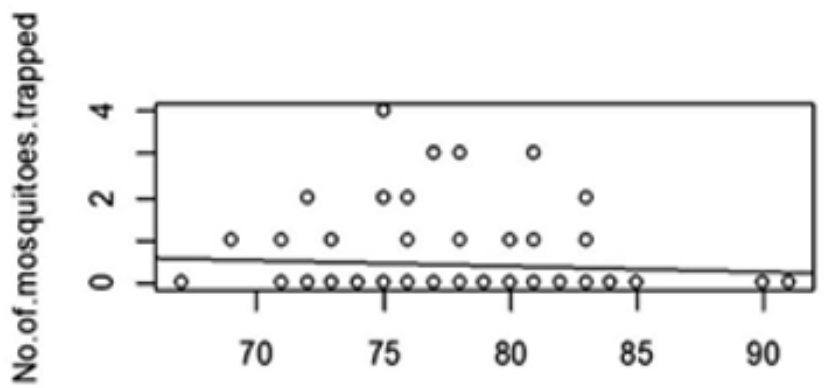

Figure 7b. Indoor Relative. Humidity (\%)

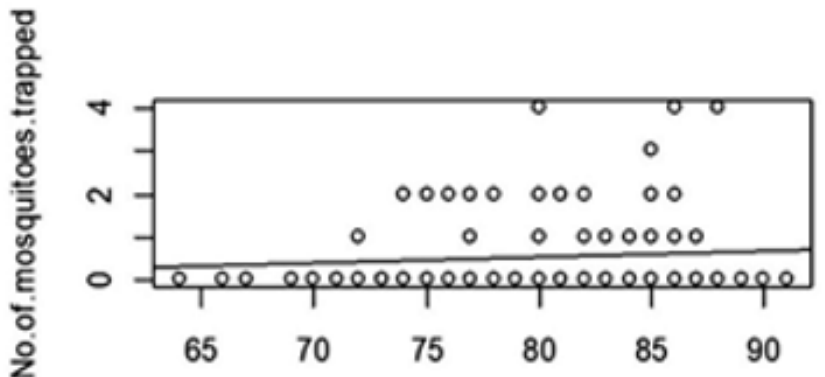

Figure 7d. Outdoor Relative.Humidity (\%)

Figure 7a-d: Association between mosquito abundance and physico-chemical parameters in concurrent feeding points.

\section{Association of An. gambiae Average Abundance to Temperature and Relative Humidity}

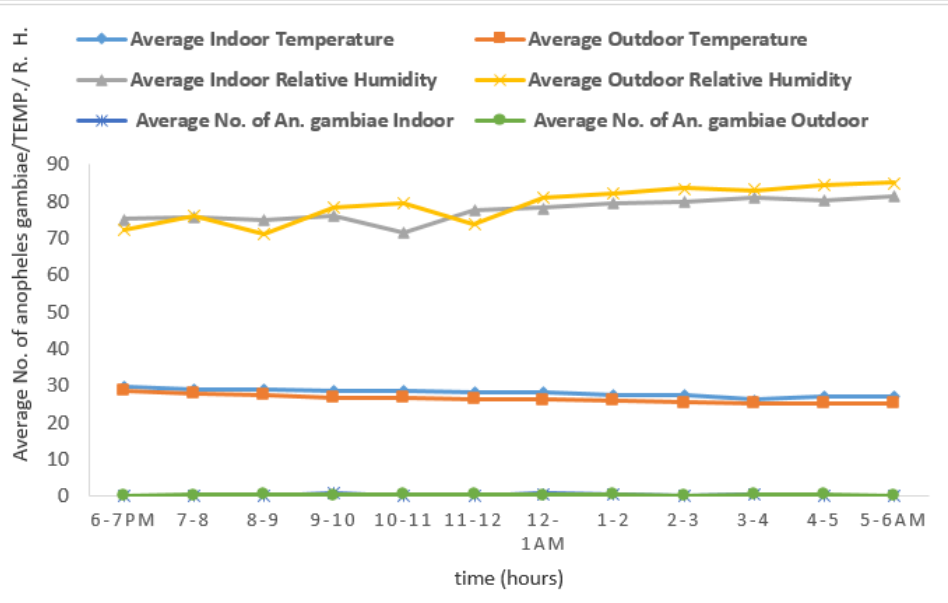

Figure 8: The simultaneous association of An. gambiae average abundance to temperature and relative humidity at both points. 
The average abundance of An. gambiae relatively increased with increase in relative humidity while temperature decreased as shown in Figure 8. This stands in agreement with the finding by Ngowo, et al. [29] who demonstrated that the malaria vector An. arabiensis shifts the location of its biting from indoors to outdoors in association with relative differences in microclimatic conditions, they prefer to bite in relatively cooler and humid places. Also, this matches with laboratory observations by Kessler and Guerin [32] where An. gambiae s.l., An. stephensi and Cx. pipiens moved toward the more humid and cooler parts of a cage such as the roof, in comparison to other parts.

\section{Man biting rate (MBR) of Mosquitoes in Relation to Indoor and Outdoor Points}

The MBR of An. gambiae per person per night was 2.6 and 3.4 An. gambiae in indoor and outdoor points respectively whereas, culicine MBR in indoor and outdoor points was 2.4 and 2.5 respectively. This is in line with work by Keana, et al. [27] who recorded indoors and outdoors MBR to be 19.9 versus 65.3/ person/night in south-central Ethiopia.

\section{Abdominal Condition of the Mosquitoes Caught}

Most of the mosquitoes caught were unfed 73 (83.9\%) followed by those fed $10(11.6 \%)$ then gravid 3 (3.4\%) while half gravid category was the least $1(1.1 \%)$ as shown in Table 4 . The high number of unfed mosquitoes may be due to the fact that they lacked access to blood meal host who were laying down safely under untreated bed nets thereby making it impossible for them to feed. A similar study showed that over $94 \%$ of the population of trapped female mosquitoes were not blood-fed and it was unclear whether these individuals are newly emerged (nulliparous) or parous females that have not yet taken a blood meal Sriwichai, et al. [23]. The fed caught mosquitoes may have wandered from nearby areas where they must have fed on blood meal host either indoor or outdoor [30-34].

Table 4: Abdominal Condition of Mosquitoes Caught in May 2018.

\begin{tabular}{|c|c|c|c|c|c|c|c|c|c|c|}
\hline \multirow[t]{2}{*}{ Species } & \multicolumn{2}{|c|}{ Unfed } & \multicolumn{2}{|c|}{ Fed } & \multicolumn{2}{|c|}{ Half gravid } & \multicolumn{2}{|c|}{ Gravid } & \multicolumn{2}{|c|}{ Total } \\
\hline & In & Out & In & Out & In & Out & In & Out & In & Out \\
\hline Ae. aegypti & 1 & 2 & 0 & 0 & 1 & 0 & 0 & 0 & 2 & 2 \\
\hline An. gambiae & 17 & 21 & 3 & 6 & 0 & 0 & 1 & 0 & 21 & 27 \\
\hline Cx. quinquefasciatus & 13 & 17 & 0 & 1 & 0 & 0 & 0 & 2 & 13 & 20 \\
\hline Mn. uniformis & 1 & 1 & 0 & 0 & 0 & 0 & 0 & 0 & 1 & 1 \\
\hline Sub-Total & 32 & 41 & 3 & 7 & 1 & 0 & 1 & 2 & 37 & 50 \\
\hline Total (\%) & \multicolumn{2}{|c|}{73 (83.9) } & \multicolumn{2}{|c|}{$10(11.6)$} & \multicolumn{2}{|c|}{$1(1.1)$} & \multicolumn{2}{|c|}{$3(3.4)$} & \multicolumn{2}{|c|}{87} \\
\hline
\end{tabular}

\section{Conclusion}

This study shows that CDC light trap is very effective and has high efficiency in trapping of mosquito species. A total of 95 mosquitoes were recorded in both indoor and outdoor points in which the anopheline group had only An. gambiae while, Cx. quinquefasciatus was the most abundant among the culicines caught. Temperature and relative humidity influences the abundance of the mosquitoes in Mararaba-Akunza Lafia, Nasarawa State. More mosquitoes were caught outdoors than indoors due to the transition period in the month of May between late dry and early wet seasons. Mosquitovectors population increased as temperature decreased with an increase in relative humidity while their population decreased as temperature increased with a decrease in relative humidity. Mosquito feeding habit in relation to time also shows that the vectors are specific in their feeding time, recording high peak feeding time at $9-10 \mathrm{pm}$ and $1-2 \mathrm{am}$ respectively. Since most of the mosquitoes were unfed there is a need in future studies for the ratio of nulliparous to parous female mosquitoes be determined through dissection. The findings from this study shows that there is need for the people to be properly and effectively educated on sanitation, environmental health, and the use of treated mosquito nets both indoors and outdoors so as to reduce human-vectors contact in the study area.

\section{References}

1. WHO (2010). Malaria in the Greater Mekong Subregion: regional and country profiles: World Health Organization. In WHO Mekong Malaria Programme.

2. Badolo A, Traore A, Jones CM, Sanou A, Flood L, Guelbeogo WM, Ranson H and Sagnon N (2012). Three Years of Insecticide Resistance Monitoring in Anopheles gambiae in Burkina Faso: Resistance on the Rise? Malaria Journal 11: 232.

3. Oyewole IO, Kolawole MA, Adedeji OC, Adeogun D and Awolola S (2018). Susceptibility pattern of Anopheles mosquito to different classes of insecticides in selected communities in Ila-Orangun, Southwest Nigeria. International Journal of Mosquito Research, 5 (1): 106-111.

4. Awolola TS, Adeogun A, Olakiigbe AK, Oyeniyi T, Olukosi YA, Okoh H, Arowolo T, Akila J, Oduola A and Amajoh CN (2018). Pyrethroids resistance intensity and resistance mechanisms in Anopheles gambiae from malaria vector surveillance sites in Nigeria. PLoS ONE 13(12): e0205230.

5. Mwansat GS, Nanvyat N, Ombugadu A, Mafuyai MJ, Lapang MP, Nkup, CD, Oduola AO, Inyama PU, Samdi LM, Okeke I and Bewa C (2019). Insecticide susceptibility status, resistance intensity and mechanism of pyrethroids resistance in An. gambiae s.l. mosquitoes from six Local Government Areas in Plateau State Nigeria. Abstract of the $50^{\text {th }}$ Annual Conference of Entomological Society of Nigeria (ESN) Yola 2019ESN24/ MVE07P 66. 
6. Oduola AO, Abba E, Adelaja O, Ande AT, Yoriyo KP, and Awolola, T. S. (2019). Widespread Report of Multiple Insecticide Resistance in Anopheles gambiae s.l. Mosquitoes in Eight Communities in Southern Gombe, North-Eastern Nigeria. Journal of Arthropod Borne Dis 13(1): 50-61.

7. Lynd A, Gonahasa S, Staedke SG, Oruni A, Maiketi-Sebuguzi C, Dorsey G, Opigo J, Yeka A, Katureebe A, Kyohere M, Hemingway J, Kamya MR and Donnelly MJ (2019). LLIN Evaluation in Uganda Project (LLINEUP): a cross-sectional survey of species diversity and insecticide resistance in 48 districts of Uganda. Parasites Vectors 12(94): 1-10.

8. Sherrard Smith E, Skarp JE, Beale AD, Fornadel C, Norris LC, Moore SJ, Mihreteab S, Charlwood JD, Bhatt S, Winskill P, Griffin JT and Churcher TS (2019). Mosquito feeding behavior and how it influences residual malaria transmission across Africa. Proceedings of the National Academy of Sciences of the United States of America 116(30): 15086-15095.

9. WHO (2019). World malaria report. 232 Pp.

10. Emidi B, Kisinza WN, Mmbando BP, Malima R and Mosha FW (2017). Anopheles and Culex mosquito larvae abundance in different breeding sites in arural setting of Muheza, Tanzania. Parasites \& Vectors 10(304): $1-12$.

11. Reisen WK, Meyer RP, Cummings RF, and Delgado O (2000). Effects of trap design and $\mathrm{CO}_{2}$ presentation on the measurement of adult mosquito abundance using Centers for Disease Control-style miniature light traps. J Am Mosq Control Assoc 16(1): 13-18.

12. Service MW (1993). Mosquito Ecology. Field Sampling Methods. London: Chapman and Hall. 988 Pp.

13. Moore SJ, Zunwei D, Hongning Z, Xuezhong W, Hongbing L, and Yujiang X (2001). The efficacy of different mosquito trapping methods in a forestfringe village, Yunnan Province, Southern China. Southeast Asian J Trop Med Public Health 32(2): 282-289.

14. Becker N, Zgomba Mand Petric D and Ludwig M (1995). Comparison of carbondioxide, octenol and a host-odour as mosquito attractants in the Upper Rhine Valley, Germany. Med Vet Entomol 9: 377-380.

15. Agidi VA, Hassan SM and Baleri TG (2017). Inter-Annual Rainfal Variability on Yam Yield in Lafia, Nasarawa State, Nigeria. PAT 13(2): 169-179.

16. Jibril AB (2017). Composition and Distribution of Mosquito Vectors and Human Strategies for Self-Protection Against Human Vector Contact in Mararaba-Akunza Community, Lafia, Nasarawa State, Nigeria. Undergraduate Thesis Submitted to Federal University of Lafia (Unpublished).

17. AIRS Nigeria (2013). End of spray report. PMI|Africa IRS (AIRS) Project Indoor Residual Spraying (IRS 2) Task Order Four. Submitted to: United States Agency for International Development/PMI p. 83.

18. Gillies MT and De Meillon B. (1968). The Anophelinae of Africa south of the Sahara (Ethiopian Zoogeographical Region). Publications of the South African Institute for Medical Research 54: 1-343.

19. Gillies MT and Coetzee M (1987). A supplement of the Anophelinae of Africa South of the Sahara (Afro tropical Region) Johannesburg: The South African Institute of Medical Research. Publications of the South African Institute for Medical Research 55: 1-143.

20. Kent RJ (2006). The Mosquito of Macha. Johns Hopkins Malaria Research Institute; Department of Molecular Microbiology and Immunology, Johns Hopkins Bloomberg School of Public Health Baltimore, MD USA, 33 Pp.
21. Williams J, Pinto J (2012) Training manual on Malaria Entomology for Entomology and Control Technicians (Basic Level). 78 Pp.

22. Ezeigwe N, Inyama PU, Samdi LM, Akila JD, Awolola TS, Mwansat GS, Anyawu GI, Yayo AM, Ebere N, Chukwuekezie O, Seyuom A, Inyang U, Kafuko J, Kolyada L, Fornadel C and Norris L (2015). Anopheles Species Diversity, Behaviour, and Sporozoite Rates in Six States of Nigeria. President's Malaria Initiative 1392: 1

23. Sriwichai P, Karl S, Samung Y, Sumruayphol S, Kiattibutr K, Payakkapol A, Mueller I, Yan G, Cui L and Sattabongkot J (2015). Evaluation of CDC light traps for mosquito surveillance in a malaria endemic area on the Thai-Myanmar border. Parasit Vectors 8: 636.

24. Norma L, Serrão ML, Melo YF, Oliveira SJ and Lourenço de Oliveira R (1998). Mosquito Frequency and Feeding Habits in an Enzootic Canine Dirofilariasis Area in Niterói, State of Rio de Janeiro, Brazil. Memórias do Instituto Oswaldo Cruz 93(2): 145-54.

25. Saavedra MP, Conn JE, Alava F, Carrasco Escobar G, Prussing C, Bickersmith SA, Sangama JL, FernandezMiñope C, Guzman M, Tong C, Valderrama C, Vinetz JM, Gamboa D and Moreno M (2019). Higher risk of malaria transmission outdoors than indoors by Nyssorhynchus darlingi in riverine communities in the Peruvian Amazon. Parasites \& Vectors 12(374): 1-15.

26. Tirados I, Costantini C, Gibson G and Torr SJ (2006). Blood-feeding behaviour of the malarial mosquito Anopheles arabiensis: implications for vector control. A Medical and Veterinary Entomology Collection 20(4): 425-437.

27. Keana O, Balkew M, Tekie H, Gebre Michael T, Deressa W, Loha E, Lindtjorn B and Overgaard HL (2016). Human biting activities of Anopheles species in south-central Ethiopia. Parasaites \& Vectors 9(1): 527.

28. Keven JB, Katusele M, Vinit R, Koimbu G, Vincent N, Thomsen EK, Karl S, Reimer LJ and Walker ED (2019). Species abundance, composition, and nocturnal activity of female Anopheles (Diptera: Culicidae) in malariaendemic villages of Papua New Guinea: assessment with barrier screen sampling. Malaria Journal 18(96): 1-12.

29. Ngowo HS, Kaindoa EW, Matthiopoulos J, Ferguson HM and Okumu FO (2017). Variations in household microclimate affect outdoor biting behavior of malaria vectors. Wellcome Open Research 2(102): 1-18.

30. Mordecai EA, Paaijmans KP, Johnson LR, Balzer C, Ben Horin T, de Moor E, McNally A, Pawar S, Ryan SJ, Smith TC and Lafferty KD (2012). Optimal temperature for malaria transmission is dramatically lower than previously predicted. Ecol Lett 16(1): 22-30.

31. Kirby MJ and Lindsay SW (2004). Responses of adult mosquitoes of two sibling species, Anopheles arabiensis and An. gambiae s.s. (Diptera: Culicidae) to high temperatures. Bull Entomol Res 94(5): 441-448.

32. Kessler S and Guerin PM (2008). Responses of Anopheles gambiae, Anopheles stephensi, Aedes aegypti, and Culex pipiens mosquitoes (Diptera: Culicidae) to cool and humid refugium conditions. J Vector Ecol 33(1): 145-149.

33. Paaijmans KP, Imbahale SS, Thomas MB and Takken W (2010). Relevant microclimate for determining the development rate of malaria mosquitoes and possible implications of climate change. Malar J 9: 196. 
ISSN: 2574-1241

DOI: 10.26717/BJSTR.2020.25.004133

Ombugadu A. Biomed J Sci \& Tech Res

(c) (P) This work is licensed under Creative Commons Attribution 4.0 License

Submission Link: https://biomedres.us/submit-manuscript.php

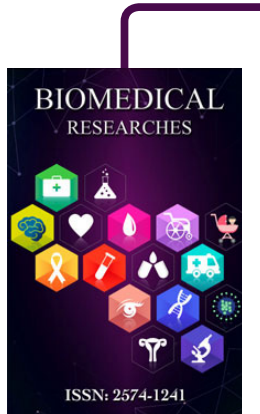

Assets of Publishing with us

- Global archiving of articles

- Immediate, unrestricted online access

- Rigorous Peer Review Process

- Authors Retain Copyrights

- Unique DOI for all articles

https://biomedres.us 